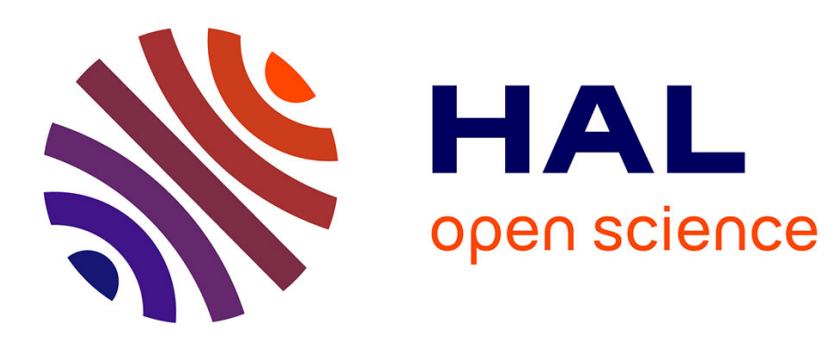

\title{
Intermolecular Rhodium(II)-Catalyzed Allylic C(sp 3)-H Amination of Cyclic Enamides
}

Romain Rey-Rodriguez, Grégory Jestin, Vincent Gandon, Gwendal Grelier, Pascal Retailleau, Benjamin Darses, Philippe Dauban, Isabelle Gillaizeau

\section{- To cite this version:}

Romain Rey-Rodriguez, Grégory Jestin, Vincent Gandon, Gwendal Grelier, Pascal Retailleau, et al.. Intermolecular Rhodium(II)-Catalyzed Allylic C(sp 3)-H Amination of Cyclic Enamides. Advanced Synthesis and Catalysis, 2018, 360 (3), pp.513-518. 10.1002/adsc.201701188 . hal-02366212

\section{HAL Id: hal-02366212 \\ https://hal.science/hal-02366212}

Submitted on 15 Nov 2019

HAL is a multi-disciplinary open access archive for the deposit and dissemination of scientific research documents, whether they are published or not. The documents may come from teaching and research institutions in France or abroad, or from public or private research centers.
L'archive ouverte pluridisciplinaire HAL, est destinée au dépôt et à la diffusion de documents scientifiques de niveau recherche, publiés ou non, émanant des établissements d'enseignement et de recherche français ou étrangers, des laboratoires publics ou privés. 
DOI: 10.1002/adsc.201((will be filled in by the editorial staff))

\title{
Intermolecular Rhodium(II)-Catalyzed Allylic C(sp3)-H Amination of Cyclic Enamides
}

\section{Romain Rey-Rodriguez, ${ }^{\mathrm{a}, \mathrm{b}}$ Grégory Jestin, ${ }^{\mathrm{a}}$ Vincent Gandon, ${ }^{\mathrm{c}}$ Gwendal Grelier, ${ }^{\mathrm{b}}$ Pascal Retailleau, ${ }^{\mathrm{b}}$ Benjamin Darses, ${ }^{\mathrm{b}}$ Philippe Dauban, ${ }^{\mathrm{b} *}$ and Isabelle Gillaizeau ${ }^{\mathrm{a} *}$}

a Institute of Organic and Analytical Chemistry, ICOA UMR 7311 CNRS, Université d'Orléans, rue de Chartres, 45100 Orléans, France

[e-mail: isabelle.gillaizeau@univ-orleans.fr]

b Institut de Chimie des Substances Naturelles, CNRS UPR 2301, Université Paris-Sud, Université Paris-Saclay, avenue de la terrasse, 91198 Gif-sur-Yvette, France

[e-mail : philippe.dauban@,cnrs.fr]

c Institut de Chimie Moléculaire et des Matériaux d'Orsay, CNRS UMR 8182, Univ. Paris-Sud, Université Paris-Saclay, 91405 Orsay, France

Received: ((will be filled in by the editorial staff))

Supporting information for this article is available on the WWW under http://dx.doi.org/10.1002/adsc.201\#\#\#\#\#.((Please delete if not appropriate))

\begin{abstract}
The intermolecular Rh(II)-catalyzed $\mathrm{C}\left(\mathrm{sp}^{3}\right)-\mathrm{H}$ amination of enamides gives access to new 4-aminopiperidine derivatives that are useful building blocks in medicinal chemistry. This efficient transformation proceeds at room temperature with complete regio- and chemoselectivity in favor of the allylic $\mathrm{C}\left(\mathrm{sp}^{3}\right)-\mathrm{H}$ bond, and has a broad functional group tolerance. In addition, the matched combination of the chiral $\mathrm{Rh}_{2}(S \text {-nta })_{4}($ nta $=(\mathrm{S})-\mathrm{N}-1,8$-naphthoylalanine $)$ with an optically pure $(S)$-sulfonimidamide allows isolation of allylic amines with excellent stereocontrol.
\end{abstract} Keywords: Allylic amination; Enamide; Heterocycle; Nitrene; Rhodium catalysis

\section{Introduction}

The ubiquity of nitrogen in life and material sciences is a source of inspiration for the design of selective C$\mathrm{N}$ bond forming reactions. Significant achievements have been made to this end through the discovery of new processes for the direct amination of $\mathrm{C}\left(\mathrm{sp}^{3}\right)-\mathrm{H}$ bonds. $^{[1]}$ Particularly, the recent development of transition metal-catalyzed nitrene $\mathrm{C}\left(\mathrm{sp}^{3}\right)-\mathrm{H}$ insertion reactions $^{[2]}$ has culminated in the design of efficient methods that make catalytic $\mathrm{C}-\mathrm{H}$ amination now a standard tool in the total synthesis of complex molecules. ${ }^{[3]}$

Catalytic allylic $\mathrm{C}\left(\mathrm{sp}^{3}\right)-\mathrm{H}$ amination raises the issue of chemoselectivity because metallanitrenes are well known to add to alkenes to afford the corresponding aziridines. ${ }^{[2-4]}$ Several solutions have first arisen from the use of tethered reagents that allow for delivering the metal-bound nitrene species in an intramolecular manner with high level of chemoselectivity. The development of fine-tuned $\mathrm{Rh}^{[5]} \mathrm{Ru}^{\left[{ }^{[6]}\right.} \mathrm{Fe},{ }^{[7]} \mathrm{Co},{ }^{[8]}$ $\mathrm{Ag},{ }^{[9]}$ and $\mathrm{Mn}^{[10]}$ complexes has proved fruitful to favor the functionalization of the allylic position. However, the corresponding intermolecular reaction is, by comparison, much more difficult to achieve. The first examples of efficient intermolecular chemoselective allylic $\mathrm{C}\left(\mathrm{sp}^{3}\right)-\mathrm{H}$ amination reactions have been recently reported following the careful design of nitrene precursors and metal complexes, ${ }^{[11],[12]}$ and these results demonstrate the need for further investigation to extend their scope.

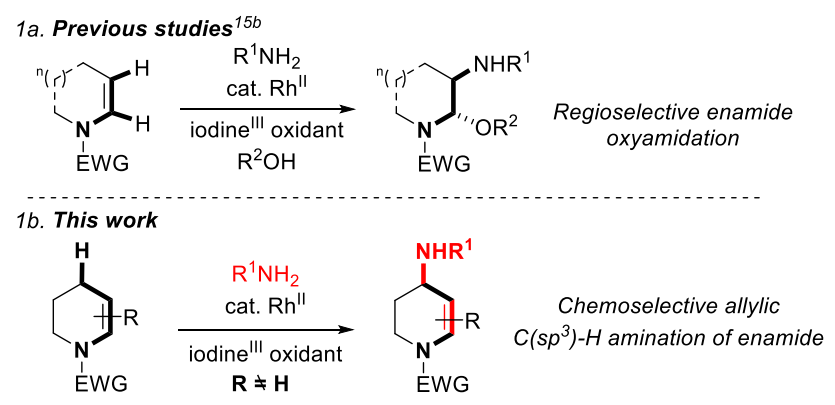

Figure 1. Background for the study. 
Another issue to address with catalytic $\mathrm{C}\left(\mathrm{sp}^{3}\right)-\mathrm{H}$ amination reactions is their application to nitrogen heterocycles. Hyperconjugative effects, particularly, are responsible for the higher reactivity of $\mathrm{C}\left(\mathrm{sp}^{3}\right)-\mathrm{H}$ bonds $\alpha$ - to the nitrogen, ${ }^{[13]}$ thereby making the remote functionalization of other sites difficult to perform, though efficient solutions have been reported. ${ }^{[14]}$ We have recently demonstrated that catalytic nitrene transfers enable the regioselective intermolecular oxyamidation of various $\pi$-bonds. ${ }^{[15]}$ Specifically, the application of rhodium-catalyzed nitrene additions ${ }^{[16]}$ to enamides and enecarbamates affords oxyaminated products in high yields, that can be further transformed via the nucleophilic displacement of the resulting $\mathrm{N}, \mathrm{O}$-acetals (Figure 1a). ${ }^{[15 b]}$ However, while exploring the scope of the reaction, a different reactivity has been uncovered for C2- or C3-substituted enamides ${ }^{[17]}$ Herein, we report a novel access to 4 -aminopiperidines, ${ }^{[18]}$ a privileged motif in medicinal chemistry (i.e. aminobenzoquinolizine) resulting from a catalytic allylic $\mathrm{C}\left(\mathrm{sp}^{3}\right)-\mathrm{H}$ amination (Figure $1 \mathrm{~b}$ ).

\section{Results and Discussion}

Previous studies have shown that the use of the $\mathrm{TcesNH}_{2} \quad$ (2,2,2-Trichloroethoxysulfonamide)/ $\mathrm{Rh}_{2}(\mathrm{esp})_{2} \quad$ (esp: $\quad \alpha, \alpha, \alpha^{\prime}, \alpha^{\prime}$-tetramethyl-1,3-benzenedipropionate) system in the presence of olefins always affords products resulting from addition to the $\pi$ bond.$^{[15,16]}$ However, application to 2-phenyl-enamide $\mathbf{1 a}^{[19]}$ of the reaction conditions previously established for enamide oxyamidation led us to observe a complete switch in the chemoselectivity of the reaction (Table 1). Thus, instead of isolating the product resulting from functionalization of the $\pi$-bond, we isolated the allylic $\mathrm{C}\left(\mathrm{sp}^{3}\right)-\mathrm{H}$ aminated derivative $\mathbf{2} \mathbf{a}$ as the sole compound. No trace of the corresponding oxyamidated derivative 3a was observed on the ${ }^{1} \mathrm{H}$ NMR spectrum of the crude reaction mixture. The high and unusual chemoselectivity of the transformation prompted us to undertake a systematic study as the intermolecular Rh-catalyzed allylic $\mathrm{C}\left(\mathrm{sp}^{3}\right)-\mathrm{H}$ amination of enamide would afford a readily efficient access to relevant 1,3 diamino motifs. A rapid screening of the oxidants and their equivalents (Table 1, entries 1-3), the catalysts and their loading (entries 4-7), the solvents (entries 8-12) and the nitrene source (entry 13) in the presence of compound 1a revealed that the best yield was obtained by using TcesNH $\mathrm{N}_{2}(1.5$ equiv) as the nitrene source, in the presence of $\mathrm{Rh}_{2}(\mathrm{esp})_{2}(2 \mathrm{~mol} \%)$ and $\mathrm{PhI}(\mathrm{OPiv})_{2}$ (2 equiv) in toluene at room temperature (entry 1). Under these conditions, the corresponding allylic aminated enamide 2 a was isolated in $90 \%$ yield after 2 hours of reaction. Amination of toluene was observed as a side reaction when $\mathrm{Rh}_{2}(\mathrm{OAc})_{4}$ was used as the catalyst (entry 5) ${ }^{[20]}$ No side reaction via the formation of the oxyamidated compound 3a was observed in the presence of $\mathrm{MeOH}$ as a solvent (entries 11-12). ${ }^{[15 b]} \mathrm{By}$ using $\mathrm{TsNH}_{2}$ as the nitrene source, no reaction occurred (entry 13). Control experiments showed no reactivity in the absence of catalyst or oxidant.

Table 1. Catalytic allylic $\mathrm{C}\left(\mathrm{sp}^{3}\right)-\mathrm{H}$ amination of $\mathbf{1 a} .^{[\mathrm{a}]}$

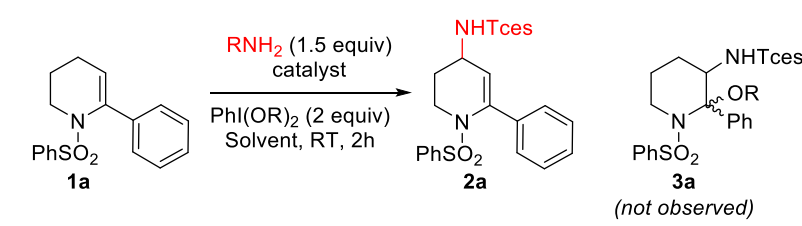

\begin{tabular}{|c|c|c|c|c|}
\hline Entry & Catalyst & Oxidant & Solvent & Yield $^{[b]}$ \\
\hline 1 & $\mathrm{Rh}_{2}(\mathrm{esp})_{2}$ & $\mathrm{PhI}(\mathrm{OPiv})_{2}$ & Toluene & $90 \%$ \\
\hline 2 & $\mathrm{Rh}_{2}(\mathrm{esp})_{2}$ & $\mathrm{PhI}(\mathrm{OAc})_{2}$ & Toluene & $88 \%$ \\
\hline $3^{c}$ & $\mathrm{Rh}_{2}(\mathrm{esp})_{2}$ & $\mathrm{PhI}(\mathrm{OPiv})_{2}$ & Toluene & $70 \%$ \\
\hline $4^{\mathrm{d}}$ & $\mathrm{Rh}_{2}(\mathrm{esp})_{2}$ & $\mathrm{PhI}(\mathrm{OPiv})_{2}$ & Toluene & $73 \%$ \\
\hline $5^{\mathrm{e}}$ & $\mathrm{Rh}_{2}(\mathrm{OAc})_{4}$ & $\mathrm{PhI}(\mathrm{OPiv})_{2}$ & Toluene & $0 \%$ \\
\hline $6^{\mathrm{d}}$ & $\mathrm{Cu}(\mathrm{OTf})_{2}$ & $\mathrm{PhI}(\mathrm{OPiv})_{2}$ & Toluene & $0 \%$ \\
\hline $7^{\mathrm{f}}$ & $\begin{array}{l}\mathrm{Cu}_{2} \mathrm{O}, \\
\text { phenantroline }\end{array}$ & $\mathrm{PhI}(\mathrm{OPiv})_{2}$ & Toluene & $0 \%$ \\
\hline 8 & $\mathrm{Rh}_{2}(\mathrm{esp})_{2}$ & $\mathrm{PhI}(\mathrm{OPiv})_{2}$ & $\left(\mathrm{CH}_{2} \mathrm{Cl}\right)_{2}$ & $45 \%$ \\
\hline 9 & $\mathrm{Rh}_{2}(\mathrm{esp})_{2}$ & $\mathrm{PhI}(\mathrm{OPiv})_{2}$ & $\mathrm{CH}_{3} \mathrm{CN}$ & $0 \%$ \\
\hline 10 & $\mathrm{Rh}_{2}(\mathrm{esp})_{2}$ & $\mathrm{PhI}(\mathrm{OPiv})_{2}$ & $\mathrm{CH}_{2} \mathrm{Cl}_{2}$ & $85 \%$ \\
\hline 11 & $\mathrm{Rh}_{2}(\mathrm{esp})_{2}$ & $\mathrm{PhI}(\mathrm{OPiv})_{2}$ & $\mathrm{CCl}_{4} / \mathrm{MeOH}(1: 1)$ & $81 \%$ \\
\hline $12^{\mathrm{g}}$ & $\mathrm{Rh}_{2}(\mathrm{esp})_{2}$ & $\mathrm{PhI}(\mathrm{OPiv})_{2}$ & $\mathrm{CCl}_{4} / \mathrm{MeOH}(1: 1)$ & $85 \%$ \\
\hline $13^{\mathrm{h}}$ & $\mathrm{Rh}_{2}(\mathrm{esp})_{2}$ & $\mathrm{PhI}(\mathrm{OPiv})_{2}$ & Toluene & $0 \%$ \\
\hline
\end{tabular}

${ }^{[a]}$ Unless otherwise specified, all reactions were carried out using: 1a $(0.17 \mathrm{mmol}), \mathrm{TcesNH}_{2}(0.25 \mathrm{mmol}), \mathrm{Rh}_{2}(\mathrm{esp})_{2}(2$ mol\%), PhI(OPiv) $2(0.33 \mathrm{mmol})$ in toluene $(2 \mathrm{ml})$ at $\mathrm{rt}$ for $2 \mathrm{~h} .{ }^{[\mathrm{b}]}$ Isolated yield. ${ }^{[c]} 1$ equiv. of oxidant was used. ${ }^{[\mathrm{d}]} 1$ mol\% of catalyst was used. ${ }^{[e]}$ The compound of $\mathrm{C}\left(\mathrm{sp}^{3}\right)-\mathrm{H}$ amination of toluene was isolated as the sole side product. [f] $1 \mathrm{~mol} \%$ of catalyst and $2 \mathrm{~mol} \%$ of ligand were used. ${ }^{[g]}$ Reaction conducted at $0{ }^{\circ} \mathrm{C}$. ${ }^{[\mathrm{h}]} \mathrm{TsNH}_{2}$ (1.5 equiv) was used as the nitrene source.

The optimized reaction conditions for $\mathrm{C}\left(\mathrm{sp}^{3}\right)-\mathrm{H}$ amination were then applied to various $\mathrm{C} 2$-substituted enamides 1a-p (Table 2) ${ }_{3}^{[19,21]}$ The high chemoselectivity for allylic $\mathrm{C}\left(\mathrm{sp}^{3}\right)-\mathrm{H}$ amination over oxyamidation was confirmed in each case. The expected allylic amines were isolated with yields of up to $90 \%$. The reaction tolerates the presence of electrondonating or electron-withdrawing groups on the aromatic ring, the corresponding products having been isolated with yields in the $35-82 \%$ range (2b-h). It is worth mentioning that yields are intertwined with the electronic properties of the aryl substituents; the lowest yields being observed for electron-withdrawing substituents (2e-h). Given the prevalence of heterocycles in medicinal chemistry, we also evaluated the tolerance of this method to enamides bearing fused aromatic or heteroaromatic ring system at $\mathrm{C} 2$, such as a naphtalene (1i), a benzothiophene (1j), an indole (1k), or a benzofuran (11). The bias of enamides $\mathbf{1 j - 1}$ toward allylic $\mathrm{C}\left(\mathrm{sp}^{3}\right)-\mathrm{H}$ amination $v s$. oxyamidation persisted, and no product arising from the competitive functionalization of the heterocyclic double bond was detected. $^{[15 \mathrm{a}]}$ This result showcases the potential 
application of this method to late stage diversification of biologically active compounds. An interesting result was also obtained starting from the enol phosphate $1 \mathrm{~m}$. The product resulting from the $\mathrm{C}\left(\mathrm{sp}^{3}\right)-$ $\mathrm{H}$ amination reaction was hydrolyzed in situ to the corresponding 4-aminopiperidin-2-one $\mathbf{2 m}$, which could be advantageously used for further functionalization. Finally, enynes $\mathbf{2 n}$ and $\mathbf{2 0}$, or enamide bearing an ester function (2p), which could serve as valuable synthetic intermediates, were tolerated.

Table 2. Rh catalyzed allylic $\mathrm{C}\left(\mathrm{sp}^{3}\right)-\mathrm{H}$ amination of $\mathrm{C} 2-$ substituted enamides 1. ${ }^{[\mathrm{a}]}$

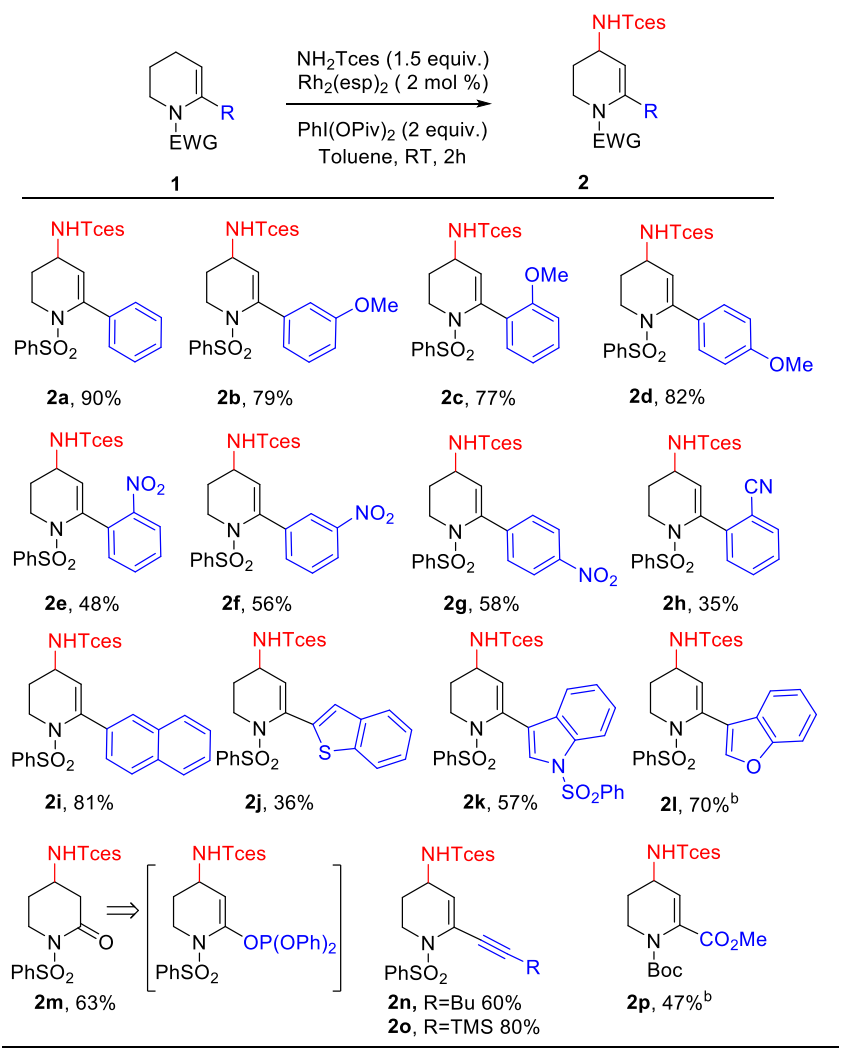

${ }^{[a]}$ Isolated yield. ${ }^{[b]} 3$ equiv. of substrate was employed.

These results then prompted us to extend the scope of the $\mathrm{C}\left(\mathrm{sp}^{3}\right)-\mathrm{H}$ amination reaction toward $\mathrm{C} 3-$ susbtituted enamides 1q-w (Table 3). ${ }^{[22]}$ Successful amination at the allylic position of $\mathbf{1 q}-\mathbf{v}$ was performed under optimized conditions to afford the corresponding new 4-amino-substituted enamides 2q$\mathbf{v}$ with complete chemoselectivity and good yields. We did not detect the formation of the corresponding oxyamidated compound 3. Both electron-donating (2r) and electron-withdrawing (2s-u) functional groups were tolerated. As observed above, the electronic nature of aryl substituents directly impacts the reactivity of the adjacent allylic $\mathrm{C}\left(\mathrm{sp}^{3}\right)-\mathrm{H}$ bond; electron-rich arenes provide the highest yields. ${ }^{[23]} \mathrm{This}$ trend was confirmed with dienamide $\mathbf{1 v}$. The presence of an electron-withdrawing substituent (i.e ester group) onto the dienamide reduces the reactivity of the proximal $\mathrm{C}\left(\mathrm{sp}^{3}\right)-\mathrm{H}$. Low yields observed in some cases were considered to be due to the instability of product 2 under the oxidative reaction conditions. It is worth mentioning that degradation was observed starting from $\mathrm{C} 2$-alkyl enamides.

Table 3. Rh catalyzed allylic $\mathrm{C}\left(\mathrm{sp}^{3}\right)-\mathrm{H}$ amination of $\mathrm{C} 3-$ substituted enamides. ${ }^{[\mathrm{a}]}$

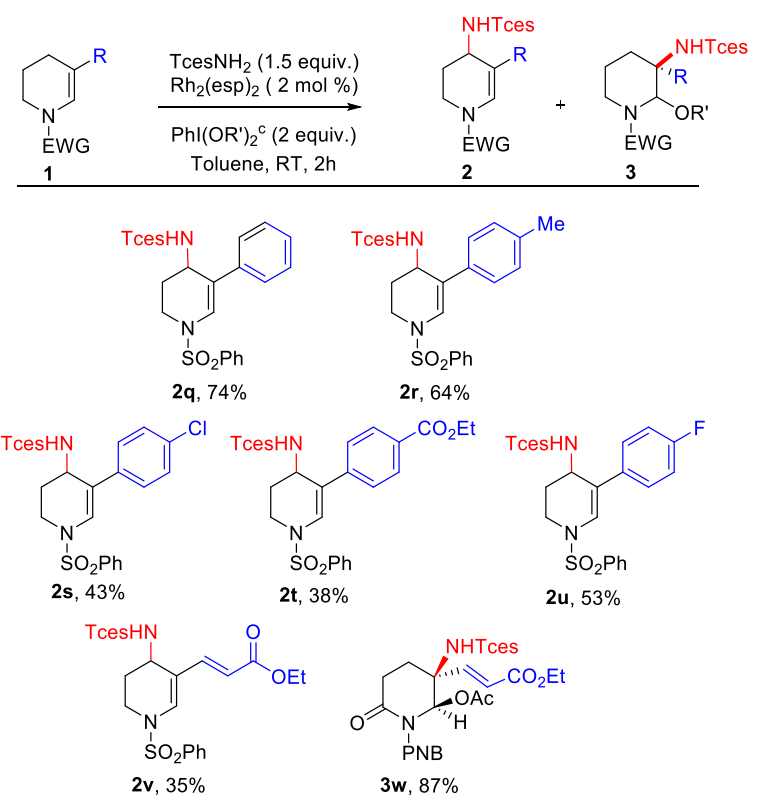

${ }^{[\mathrm{a}]}$ Isolated yield. ${ }^{[\mathrm{b}]}$ Chemoselectivity determined by crude ${ }^{1} \mathrm{H}$ NMR. ${ }^{[c]} \mathrm{PhI}(\mathrm{OAc})_{2}$ or $\mathrm{PhI}(\mathrm{OPiv})_{2}$ was used, see Supporting Information.

These results then prompted us to extend the scope of the $\mathrm{C}\left(\mathrm{sp}^{3}\right)-\mathrm{H}$ amination reaction toward $\mathrm{C} 3-$ susbtituted enamides 1q-w (Table 3). ${ }^{[22]}$ Successful amination at the allylic position of $\mathbf{1 q}-\mathbf{v}$ was performed under optimized conditions to afford the corresponding new 4-amino-substituted enamides 2q$\mathbf{v}$ with complete chemoselectivity and good yields. We did not detect the formation of the corresponding oxyamidated compound 3. Both electron-donating (2r) and electron-withdrawing (2s-u) functional groups were tolerated. As observed above, the electronic nature of aryl substituents directly impacts the reactivity of the adjacent allylic $\mathrm{C}\left(\mathrm{sp}^{3}\right)-\mathrm{H}$ bond; electron-rich arenes provide the highest yields. ${ }^{[23]}$ This trend was confirmed with dienamide $\mathbf{1 v}$. The presence of an electron-withdrawing substituent (i.e ester group) onto the dienamide reduces the reactivity of the proximal $\mathrm{C}\left(\mathrm{sp}^{3}\right)-\mathrm{H}$. Low yields observed in some cases were considered to be due to the instability of product 2 under the oxidative reaction conditions. Moreover, these C3-substituted compounds also permitted us to assess the influence of the $N$-protecting group on the chemoselectivity of this process. Thus, allylic amination was observed starting from the $\mathrm{N}$ (sulfonyl) dienamide $1 \mathbf{v}$ whereas use of the ( $p$ nitrobenzyl) endo-dienamide $\mathbf{1 w}$ led to a complete switch of reactivity. Allylic amination was thus disfavored in presence of the enamide $\mathbf{1 w}$, although C3-substituted, but electronically deactivated. The oxyamidated product $\mathbf{3 w}$ was isolated in $87 \%$ yield as the sole product with a complete diastereoselectivity in 
favor of the cis isomer. ${ }^{[24]}$ It is also noteworthy that no reaction occurred with 2,3-disubstituted enamide, probably due to steric hindrance. ${ }^{[25]}$

Table 4. Diastereoselective Rh-catalyzed $\mathrm{C}\left(\mathrm{sp}^{3}\right)-\mathrm{H}$ amination of enamides $1{ }^{[\mathrm{a}]}$

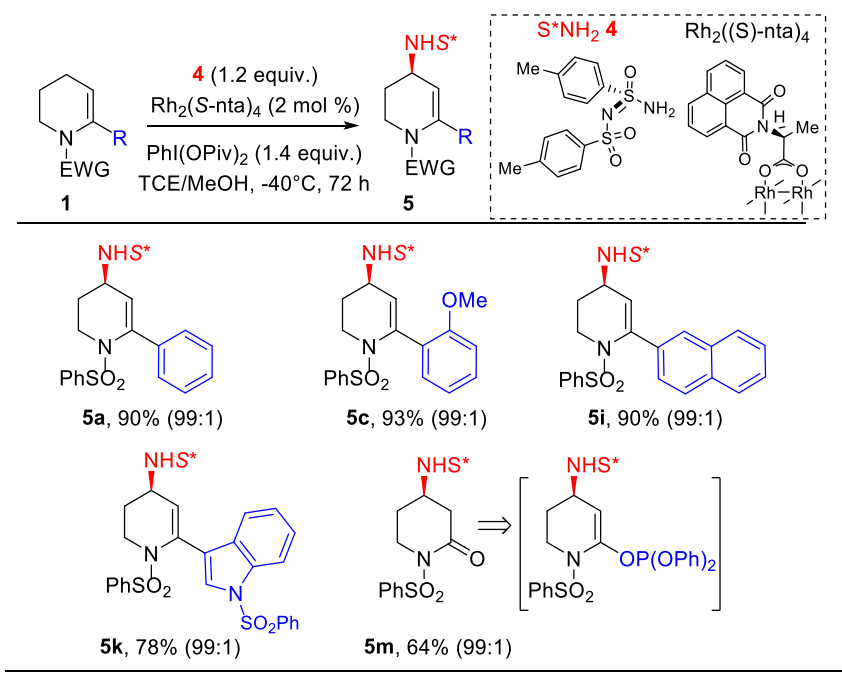

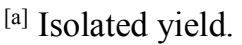

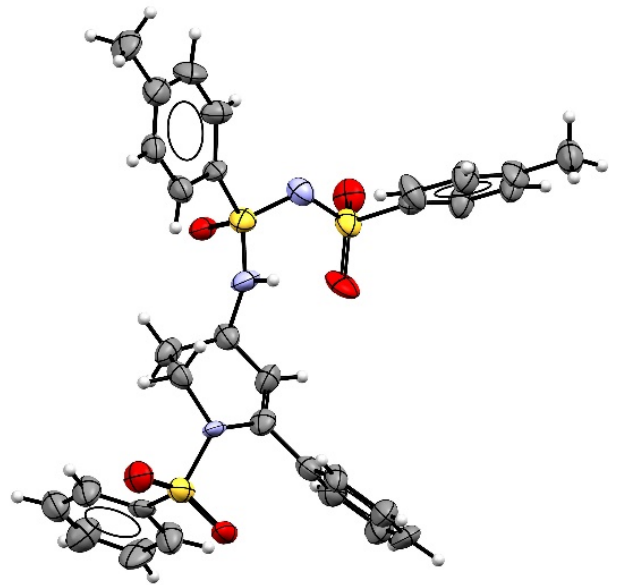

Figure 2. X-ray structure of 5a.

The chemoselectivity observed for the allylic C(sp3)$\mathrm{H}$ amination of enamides convinced us to consider whether we could also reach the same selectivity with the conditions previously reported for the stereoselective amination of hydrocarbons. ${ }^{[11 \mathrm{~b}-\mathrm{d}]}$ This $\mathrm{C}\left(\mathrm{sp}^{3}\right)-\mathrm{H}$ functionalization reaction involves the combination of the chiral rhodium complex $\mathrm{Rh}_{2}(S-$ nta $)_{4}($ nta $=(S)-N-1,8$-naphthoylalanine $)$ with an optically pure chiral nitrene precursor, i.e. the $(S)$ sulfonimidamide 4 (Table 4$){ }^{\left[{ }^{[26]}\right.}$ This matched pair of reagents has been shown to promote the amination of benzylic and allylic substrates as well as that of alkanes, enol ethers and terpenes with high yields and excellent stereocontrol. If successful with enamides, it should give access to optically pure heterocyclic structures. Pleasingly, in presence of the $(S)$ - sulfonimidamide 4 and the chiral complex $\mathrm{Rh}_{2}(S \text {-nta })_{4}$, the 2-phenylenamide 1a led exclusively to the chiral allylic amide $5 \mathbf{a}$ isolated in $90 \%$ yield as the single $(R)$ isomer by analogy with our previous studies. ${ }^{[1 \mathrm{~b}, 26]}$ Notably, the X-ray crystal structure of 5a confirmed the stereochemistry of the 4-amino enamides 5 (Figure 2). ${ }^{[27]}$ The 4 -amino enamides $\mathbf{5 c}, \mathbf{5 i}, \mathbf{5 k}$, and $\mathbf{5 m}$ were subsequently obtained with yields in the $64-93 \%$ range as single diastereoisomers. It is worth mentioning that $\mathbf{5 m}$ thereby offers the possibility of performing further functionalization. ${ }^{[28]}$ However, contrary to what was observed in Table 3 using the TcesNH${ }_{2} / \mathrm{Rh}_{2}(\text { esp })_{2}$ system, no reaction occurred starting from C3substituted enamides, because the stereoselective $\mathrm{C}\left(\mathrm{sp}^{3}\right)-\mathrm{H}$ amination with sulfonimidamides is sensitive to steric hindrance as observed in our previous studies. ${ }^{[11 \mathrm{~b}, \mathrm{c}]}$

\section{Conclusion}

In summary, we have demonstrated that the chemoselectivity of catalytic nitrene additions can be tuned by the substitution of the alkene in the case of cyclic enamides. Thus, the presence of a C2- or a C3substituent prevents the nitrene transfer from proceeding at the double bond, and the enamides undergo an intermolecular rhodium-catalyzed allylic $\mathrm{C}\left(\mathrm{sp}^{3}\right)-\mathrm{H}$ amination to afford the corresponding amines with yields of up to $90 \%$. This result underscores the ability of the sulfamate $/ \mathrm{Rh}_{2}(\mathrm{esp})_{2}$ system to react preferentially with allylic $\mathrm{C}\left(\mathrm{sp}^{3}\right)-\mathrm{H}$ bonds in an intermolecular process affording new $\mathrm{C} 4-$ aminated enamides under mild conditions. Excellent reactivity and diastereoselectivity were also observed using a combination of the $(S)$-sulfonimidamide $\mathbf{4}$ and the chiral rhodium catalyst $\left(\mathrm{Rh}_{2}(S \text {-nta })_{4}\right.$. This reaction paves the way to the synthesis of complex biologically active molecules and/or for late stage diversification. Further investigations on expanding the scope and applications of this method are underway in our laboratory.

\section{Experimental Section}

\section{General procedure for C4-aminated enamides 2.}

In an oven-dried sealable tube, enamide $1(0.17 \mathrm{mmol}, 1$ equiv) was dissolved in dry toluene $(2 \mathrm{~mL})$. TcesNH $\mathrm{TH}_{2}(57$ $\mathrm{mg}, 0.25 \mathrm{mmol}, 1.5$ equiv), $\mathrm{Rh}_{2}$ (esp) 2 ( $3 \mathrm{mg}, 0.0034 \mathrm{mmol}$, 0.02 equiv), and PhI(OPiv) 2 ( $138 \mathrm{mg}, 0.34 \mathrm{mmol}, 2$ equiv) were successively added and the reaction was stirred at room temperature for 2 hours. After completion of the reaction, the filtrate was concentrated in vacuo and the residue was purified by column chromatography on silica gel (petroleum ether/ethyl acetate) to afford the C4aminated enamide 2 .

\section{General procedure for C4-aminated enamides 5 .}

In an oven-dried sealable tube, enamide $1(0.2 \mathrm{mmol}, 1$ equiv), $\mathrm{Rh}_{2}(S$-nta) 4 (5 mg, $0.004 \mathrm{mmol}, 0.02$ equiv), (-)- $N-$ ( $p$-toluenesulfonyl)- $p$-toluenesulfonimidamide 4 (78 $\mathrm{mg}$ $0.24 \mathrm{mmol}, 1.2$ equiv) and $4 \AA$ molecular sieves (100 mg) were successively added, the tube was capped with rubber 
septum then purged three times with argon. 1,1,2,2tetrachloroethane $(0.75 \mathrm{~mL})$ and methanol $(0.25 \mathrm{~mL})$ were added under argon. The tube was cooled to $-78^{\circ} \mathrm{C}$ and bis(tert-butylcarbonyloxy)iodobenzene $(114 \mathrm{mg}, 0.28$ mmol, 1.4 equiv) was added. The reaction was stirred at $35^{\circ} \mathrm{C}$ for 3 days. The filtrate was concentrated in vacuo and the residue was purified by column chromatography on silica gel using petroleum ether/ethyl acetate as eluent to give the desired product $\mathbf{5}$ isolated as unique diastereoisomer $(>99: 1)$.

\section{Acknowledgements}

The authors thank the French National Research Agency (program $n^{\circ}$ ANR-11-IDEX-0003-02, CHARMMMAT ANR-11-LABX-0039, SynOrg ANR-11-LABX-0029, and ANR-15-CE29-0014-01) for financial support and fellowships (G. J., R. R.-R.).

\section{References}

[1] a) H. M. L. Davies, J. R. Manning, Nature 2008, 451, 417-424; b) F. Collet, R.H. Dodd, P. Dauban, Chem. Commun. 2009, 5061-5074 ; c) D. N. Zalatan, J. Du Bois, Top. Curr. Chem. 2010, 292, 347-378; d) J. L. Jeffrey, R. Sarpong, Chem. Sci. 2013, 4, 4092-4106; e) S. Chiba, H. Chen, Org. Biomol. Chem. 2014, 12, 4051-4060 ; f) M.-L. Louillat, F. W. Patureau, Chem. Soc. Rev. 2014, 43, 901-910; g) R. R. Karimov, A. Sharma, J. F. Hartwig, ACS Cent. Sci. 2016, 2, 715-724; h) Y. Park, Y. Kim, S. Chang, Chem. Rev. 2017, 117, 9247-9301.

[2] a) P. Müller, C. Fruit, Chem. Rev. 2003, 103, 29052960 ; b) M. M. Díaz-Requejo, P. J. Pérez, Chem. Rev. 2008, 108, 3379-3394; c) K. Huard, H. Lebel, Chem. Eur. J. 2008, 14, 6222-6230; d) S. Fantauzzi, A. Caselli, E. Gallo, Dalton Trans. 2009, 5434-5443; e) T. G. Driver, Org. Biomol. Chem. 2010, 8, 3831-3846; f) J. W. W. Chang, T. M. U. Ton, P. W. H. Chan, Chem. Rec. 2011, 11, 331-357; g) J. L. Roizen, M. E. Harvey, J. Du Bois, Acc. Chem. Res. 2012, 45, 911-922; h) T. Uchida, T. Katsuki, Chem. Rec. 2014, 14, 117-129; i) R. J. Scamp, J. W. Rigoli, J. M. Schomaker, Pure Appl. Chem. 2014, 86, 381-393; j) J. Buendia, G. Grelier, P. Dauban, $A d v$. Organomet. Chem. 2015, 64, 77-118.

[3] a) D. Karila, R. H. Dodd, Curr. Org. Chem. 2011, 15, 1507-1538; b) J. Egger, E. M. Carreira, Nat. Prod. Rep. 2014, 31, 449-455; c) B. Darses, R. Rodrigues, L. Neuville, M. Mazurais, P. Dauban, Chem. Commun. 2017, 53, 493-508.

[4] L. Degennaro, P. Trinchera, R. Luisi, Chem. Rev. 2014, 114, 7881-7929.

[5] a) D. N. Zalatan, J. Du Bois, J. Am. Chem. Soc. 2008, 130, 9220-9221 ; b) K. W. Fiori, C. G. Espino, B. H. Brodsky, J. Du Bois, Tetrahedron 2009, 65, 3042-3051.

[6] M. E. Harvey, D. G. Musaev, J. Du Bois, J. Am. Chem. Soc. 2011, 133, 17207-17216.

[7] S. M. Paradine, M. C. White, J. Am. Chem. Soc. 2012, 134, 2036-2039.

[8] H. Lu, H. Jiang, Y. Hu, L. Wojtas, X. P. Zhang, Chem. Sci. 2011, 2, 2361-2366.
[9] a) J. W. Rigoli, C. D. Weatherly, J. M. Alderson, B. T. Vo, J. M. Schomaker, J. Am. Chem. Soc. 2013, 135, 17238-17241; b) R. J. Scamp, J. G. Jirak, N. S. Dolan, I. A. Guzei, J. M. Schomaker, Org. Lett. 2016, 18, 30143017.

[10] S. M. Paradine, J. R. Griffin, J. Zhao, A. L. Petronico, S. M. Miller, M. C. White, Nat. Chem. 2015, 7, 987-994.

[11] a) N. S. Dolan, R. J. Scamp, T. Yang, J. F. Berry, J. M. Schomaker, J. Am. Chem. Soc. 2016, 138, 14658-14667; b) C. Liang, F. Collet, F. Robert-Peillard, P. Müller, R. H. Dodd, P. Dauban, J. Am. Chem. Soc. 2008, 130, 343350; c) C. Lescot, B. Darses, F. Collet, P. Retailleau, P. Dauban, J. Org. Chem. 2012, 77, 7232-7240; d) J. Buendia, B. Darses, P. Dauban, Angew. Chem. Int. Ed. 2015, 54, 5697-5701. For a recent comprehensive review on allylic amination, see: e) R. L. Grangea, E. A. Clizbeb, P. A. Evans, Synthesis 2016, 48, 2911-2968.

[12] For other relevant studies in the area of chemoselective intermolecular C(sp3)-H amination, see: a) J. L. Roizen, D. N. Zalatan, J. Du Bois, Angew. Chem. Int. Ed. 2013, 52, 11343-11346; b) E. N. Bess, R. J. DeLuca D. J. Tindall, M. S. Oderinde, J. L. Roizen, J. Du Bois, M. S. Sigman, J. Am. Chem. Soc. 2014, 134, 5783-5789; c) J. Wang, C. Zhao, Y. Weng, H. Xu, Catal. Sci. Technol., 2016, 6, 5292-5303.

[13] a) S. Toumieux, P. Compain, O. R. Martin, M. Selkti, Org. Lett. 2006, 8, 4493-4496; b) S. Wang, D. Romo, Angew. Chem. Int. Ed. 2008, 47, 1284-1286; c) M. Kono, S. Harada, T. Nemoto, Chem. Eur. J. 2017, 23, 74287432 .

[14] a) J. M. Howell, K. Feng, J. R. Clark, L. J. Trzepkowski, M. C. White, J. Am. Chem. Soc. 2015, 137, 1459014593; b) Y.-J.Liu, H. Xu, W.-J. Kong, M. Shang, H.-X. Dai, J.-Q. Yu Nature 2014, 515, 389-393.

[15] a) S. Beaumont, V. Pons, P. Retailleau, R. H. Dodd, P. Dauban, Angew. Chem. Int. Ed. 2010, 49, 1634-1637; b) N. Gigant, G. Dequirez, P. Retailleau, I. Gillaizeau, P. Dauban Chem. Eur. J. 2012, 18, 90-94; c) G. Dequirez, J. Ciesielski, P. Retailleau, P. Dauban, Chem. Eur. J. 2014, 20, 8929-8933; d) J. Ciesielski, G. Dequirez, P. Retailleau, V. Gandon, P. Dauban, Chem. Eur. J. 2016, 22, 9338-9347.

[16] a) K. Guthikonda, J. Du Bois, J. Am. Chem. Soc. 2002, 124, 13672-13673 ; b) K. W. Fiori, J. Du Bois, J. Am. Chem. Soc. 2007, 129, 562-568.

[17] N. Gigant, L. Chausset-Boissarie, I. Gillaizeau, Chem. Eur. J. 2014, 20, 7548-7564.

[18] P. Mattei, M. Boehringer, P. Di Giorgio, H. Fischer, M. Hennig, J. Huwyler, B. Koçer, B. Kuhn, B. M. Loeffler, A. MacDonald, R. Narquizian, Bioorg. Med. Chem., 2010, 20, 1109-1113.

[19] a) 2-substituted enamides 1 were synthesized by $\mathrm{Pd}$ cross-coupling reaction starting from enol phosphate derivatives: D. Mousset, I. Gillaizeau, J. Hassan, F. Lepifre, P. Bouyssou, G. Coudert, G. Tetrahedron Lett. 2005, 21, 3703-3705 and see Supporting Informations. 
[20] D. A. Powell, H. Fan, J. Org. Chem. 2010, 75, 27262729.

[21] Various 5-, 6- and 7-membered ring cyclic enamides were prepared but the $\mathrm{C}\left(\mathrm{sp}^{3}\right)-\mathrm{H}$ amination reaction proved successful only from the 6-membered ring compounds.

[22] N. Gigant, L. Chausset-Boissarie, I. Gillaizeau, Org. Lett. 2013, 15, 816-819 ; d) N. Gigant, L. ChaussetBoissarie, M.-C. Belhomme, T. Poisson, X. Pannecoucke, I. Gillaizeau, Org. Lett. 2013, 15, 278281; e) N. Gigant, I. Gillaizeau, Org. Lett. 2012, 14, 3304-3307.

[23] See also: a) T. Newhouse, P. S. Baran, Angew. Chem. Int. Ed., 2011, 50, 3362-3374; b) A. G. H. Wee, B. Liu, D. D. McLeod, J. Org. Chem. 1998, 63, 4218-4227.

[24] The stereochemistry was unambiguously established by NMR 1D and 2D (see Supporting Information).

[25] Molecular orbital coefficients of C2-Ph substituted enamide 1a, $\mathrm{C} 3-\mathrm{Ph}$ substituted enamide $1 \mathrm{q}$ and nonsubstituted enamide were obtained by DFT computations (see the Supporting Information), but they did not allow to rationalize the selectivity.
[26] Our previous studies have shown that both chiral reagents are needed to secure good yields and stereocontrol. Moreover, the synthesis of known enantiopure amines and several X-ray crystallographic studies of various allylic products have demonstrated that $(R)$-enantiomers of the $\mathrm{C}-\mathrm{H}$ aminated compounds are obtained by combining the $(S)$-sulfonimidamide with the $(S)$-rhodium complex. See: ref. 11b. (a) C. Liang, F. Robert-Peillard, C. Fruit, P. Müller, R. H. Dodd, P. Dauban, Angew. Chem. Int. Ed. 2006, 45, 4641-4644. (b) M. Mazurais, C. Lescot, P. Retailleau, P. Dauban, Eur. J. Org. Chem. 2014, 66-79.

[27] CCDC 1584973 (5a) contains the supplementary crystallographic data for this paper. This data is provided free of charge by the Cambridge Crystallographic Data Centre.

[28] a) X.-H. Hu, X.-F. Yang, T.-P. Loh, Angew. Chem. Int. Ed., 2015, 54, 15535-15539 and references cited herein; b) E. Claveau, I. Gillaizeau, A. Bruel, G. Coudert, J. Org. Chem. 2007, 72, 4832-4836. 


\section{FULL PAPER}

Intermolecular Rhodium(II)-Catalyzed Allylic C(sp3)-H Amination of Cyclic Enamides

Adv. Synth. Catal. Year, Volume, Page - Page

Romain Rey-Rodriguez, Grégory Jestin, Vincent Gandon, Gwendal Grelier, Pascal Retailleau, Benjamin Darses, Philippe Dauban, ${ }^{*}$ and Isabelle

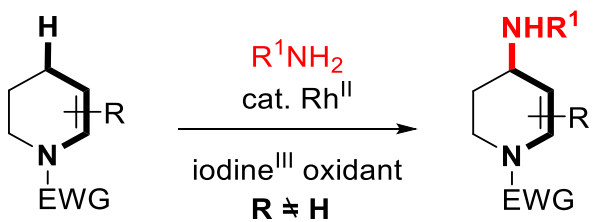
up to $90 \%$ yield high diastereoselectivity up to 99:1 Gillaizeau* 